\title{
PHYSICAL PROPERTIES OF LATVIAN HEMP FIBRES
}

\author{
I.Baltiņa $^{1}$, Z.Zamuška ${ }^{1}$, V.Stramkale ${ }^{2}$, G.Strazds ${ }^{3}$ \\ 1- Riga Technical University, Institute of Textile Material Technologies and Design \\ Āzenes Str.14/24 - 265, Riga, Latvia, LV 1048 \\ Ph.: +(371)67089822, fax: +(371)67089349, e-mail: ilze.baltina@rtu.lv \\ 2- Agriculture Science Centre of Latgale \\ Kulturas sq. 1a, Vilani, Rezeknes distr., LV 4650 \\ Ph.: +371 64628140, +371 29465004, e-pasts: strzin@apollo.lv \\ 3- Association of Textile and Clothing Industry \\ Ph.: +37129488338
}

\begin{abstract}
Each year more and more people focus on healthy, ecological and environmental-friendly living. Environmentally friendly lifestyle doesn't mean that we are using only natural products, but attention is pointed to the manufacturing and production process also. The rapid development of recycled and biodegradable products causes expanding usage of hemp fibers both in household and technical textiles. The analysis of hemp cultivation and usage trends in the world and Europe shows that hemp cultivation and processing in Latvia has good perspectives.

Product quality is influenced by raw materials. In this case it is hemp fiber descriptive characteristics. Hemp fibers are natural fibers and their properties varies according to plant growing regional climatic conditions, amount of manure, plant density, harvesting time and pre-treatment technological processes. There are studied the influence of above mentioned factors on chemical composition, geometrical and physical properties of the Latvian hemp fiber both local and foreign cultivars.

The work was carried out in cooperation between Riga Technical University, Textile Technology and Design Institute and the Agriculture Science Centre of Latgale.
\end{abstract}

Keywords: Cannabis Sativa, hemp fibers, fibre content, fibre flexibility, fibre tenacity, fibre extension.

\section{Introduction}

With the development of recycled and biodegradable raw materials increases the use of hemp fiber both in household and technical textiles. Mainly hemp in Latvia is grown for seed production. In 2008 and 2009 some individual farms sown hemp for fibre production. As in Latvia there was no experience, knowledge and skills of hemp cultivation and fiber production the Riga Technical University together with the Agriculture Science Centre of Latgale started scientific research work on hemp fibre analysis The main tasks of the present work is to evaluate the various foreign varieties and domestic variety Purini to identify the most appropriate harvesting time for the best quality of hemp fiber. The fiber quality is determined by the chemical and physical properties.

British scientists [1] studied five different varieties of hemp (Chamaeleon, Futura, Fedora, Beniko and Bialobrzeskie) to determine cultivation facilities in their country. The highest percentage of fibers derived from Beniko variety of plants. From this variety also the longest fibers are produced.

Fiber quality greatly is affected by its chemical composition. The chemical components of hemp fibre are: cellulose, hemicellulose, lignin, water and solvent soluble substances, wax, ash, pectin, protein and water. Lignin is a complex three-dimensional polymer whose function is to connect elementary fibers in bundles, therefore the more is lignin content the stiffer is fibre structure [2].

According to the literature [2-7] cellulose percentage is $73.98-77.89 \%$, hemicellulose - 3.7 to 19.76 , lignin content can be very variable $-1.75-10.6 \%$. 
According to the datas of different authors hemp fiber strength can be from $10.9 \mathrm{cN} /$ tex up to $52.40 \mathrm{cN} /$ tex [2,3]. Hemp fiber properties affects the plant growth climate. It can be concluded [7] that fiber strength can be influenced by the amount of moisture and the windy weather during plant growing. Hemp plant growing conditions influence not only fiber mechanical properties, but also their geometrical dimensions - stem length, fiber fineness. Fiber chemical composition, fineness and mechanical strength are influenced by straw cutting time. The smallest lignin content in fibers are at the beginning of flowering [9]. During flowering and seed maturation lignin content increases. In this time increases also fiber thickness. It can be concluded that the best hemp fiber harvesting time is early blooming.

\section{Materials and methods}

Hemp fibers are obtained from Cannabis Sativa plants grown in the experimental fields of Agriculture Science Centre of Latgale in 2010. There were used nine varieties of foreign hemp: Bialobrzeskie, Beniko, Epsilon 68, Fedora 17, Felina 32, Santhica 27, Futura 75, USO 31, Finola, and the local variety Purini. Basically plants of all varieties, other than Purini, grown in test plots $1 \times 1 \mathrm{~m}$ in three replications. Amount of seeds sown is so to provide 400 germinating plants to $1 \mathrm{~m}^{2}$. Hemp plants Purini grown in the wider area.

Seeds sowed in 11th May. 17th May marked hemp sprouting. The second decade of the May was warm and the average air temperature for $5.5^{\circ} \mathrm{C}$ was higher than normal, but rainfall was below the norm, and amounted to $82.3 \%$. The mean air temperature in the third decade of May decreased and for $0.4^{\circ} \mathrm{C}$ was lower than normal, but rainfall was $70 \%$ of the norm. Average air temperature of June for $0.6^{\circ} \mathrm{C}$ was higher than normal and precipitation was normal. July and the first and second decade of August was hot and sunny. In July the average temperature exceeded the norm by $4.8^{\circ} \mathrm{C}$, and rainfall accounted for $31 \%$ of the norm. Third decade of August temperature was normal, but precipitation was $38 \%$ of the norm. Hot and dry weather negatively affected the growth of hemp. Plants drooping were a result of the great heat and lack of moisture. The daily air temperature of the first decade of September was by $3.7^{\circ} \mathrm{C}$ lower than normal, but precipitation $105 \%$ of the norm.

Hemp completely was harvested from the first to 15th September. Hemp straw samples for fibre quality assessment were taken on the fourth of August and after harvesting in September. Because of the different growing time, the most part of the varieties in the August 4 didn't flower yet, Finola and USO31hemp varieties had already faded, but Purini hemp was still blooming.

Experimentally there was tested:

- Straw length;

- Straw productivity;

- Percentage of obtained fibres from the straws;

- Fiber linear density;

- Fiber bending;

- Fiber tenacity;

- Fiber extension.

From the selected fibres there were made bundles with weight $100-300 \mathrm{~g}$. Fibers were straightened and held for several days under load. Fiber bundles at least 24 hours were aged under normal climatic conditions before the experiments.

Ten bundles were used to determine the fiber linear density. From the bundles there were cut out middle parts with the length approximately $50 \mathrm{~mm}$ and mass 0.7 to $0.8 \mathrm{~g}$. $10 \mathrm{~mm}$ long middle parts of each fiber bundle were cut out. After that fibres were counted. As one fibre there were counted undivided fibers or those fibres which are split less than half of the length. If the fiber was split into two or more parts and each of them is longer than half of the sample, then each branch treated as a separate fiber. 
The fiber linear density can be calculated as follows:

$$
T=\frac{m}{n \cdot l}
$$

where

$$
\begin{aligned}
& T \text {-linear density, Tex; } \\
& m \text {-mass of the sample, } \mathrm{mg} ; \\
& n \text {-count of the fibres; } \\
& 1 \text {-sample length, } \mathrm{m} .
\end{aligned}
$$

For the measurements of fibre flexibility there was used tester F - 2. The flexibility of fiber bundles was characterized by the bending of bundle ends from the horizontal position.

There was used universal tester from Instron to determine fibre bundle tenacity and extension at break. Sample length - $10 \mathrm{~mm}$, selected speed $-15 \mathrm{~mm} / \mathrm{min}$. Pretension was not applied, because the fibers are rigid and elongation abilities are limited.

For fiber flexibility, tensile strength and elongation testing bundles at first were prepared as described above. After that $270 \mathrm{~mm}$ long the middle parts were cut out. From the middle parts there were formed 30 new fiber bundles with the mass $420 \pm 20 \mathrm{mg}$.

\section{Results and discussion}

Straw length measured before hemp harvesting (see Fig.1.). The longest ones are Futura75, Santhica27, Fedora17 and Felina32 varieties of hemp, but the shortest Finola straws.

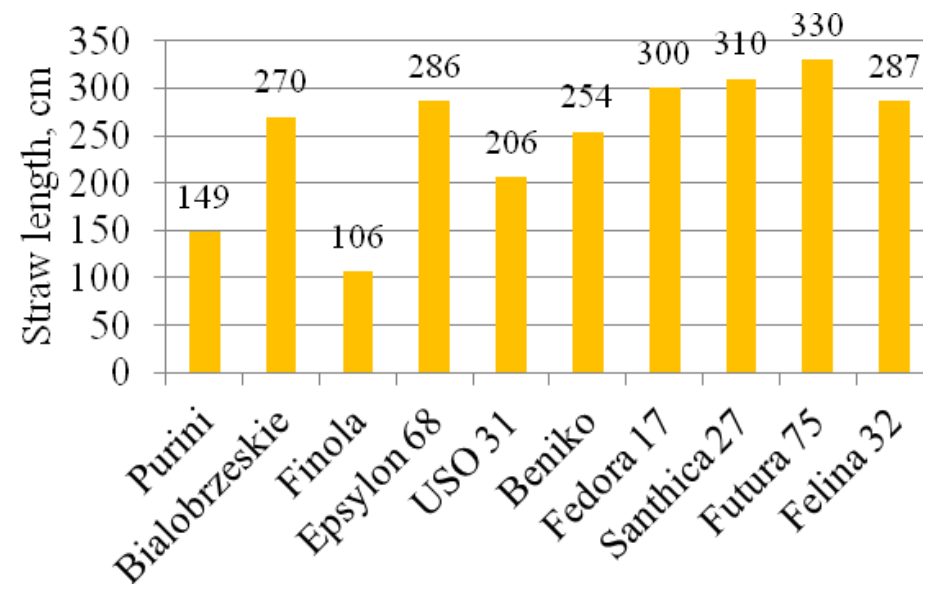

Fig.1. Straw length of different varieties

Taking into account that foreign varieties have been cropped in small areas, but Purini grown in wider area, the productivity of this variety can't be compared with other ones. In the fig. 2 there is given straw productivity of foreign varieties.

The highest straw productivity obtained from Futura, Santhica and Epsylon, but the lowest from Finola hemp variety.

Fig. 3 reflected the fiber content in the straws. The largest content is for the variety Beniko, but the smallest one in the varieties Purini and Finola. Taking into account the straw productivity and fiber percentage in them, there was calculated the amount of obtained fibre from one square meter.

As it is shown in Fig.4 the largest amount of fiber can be obtained from Santhica 27, Futura 75 and Felina 32 hemp varieties.

Futher there is determined certain fiber properties and their variations according to plant maturity. 


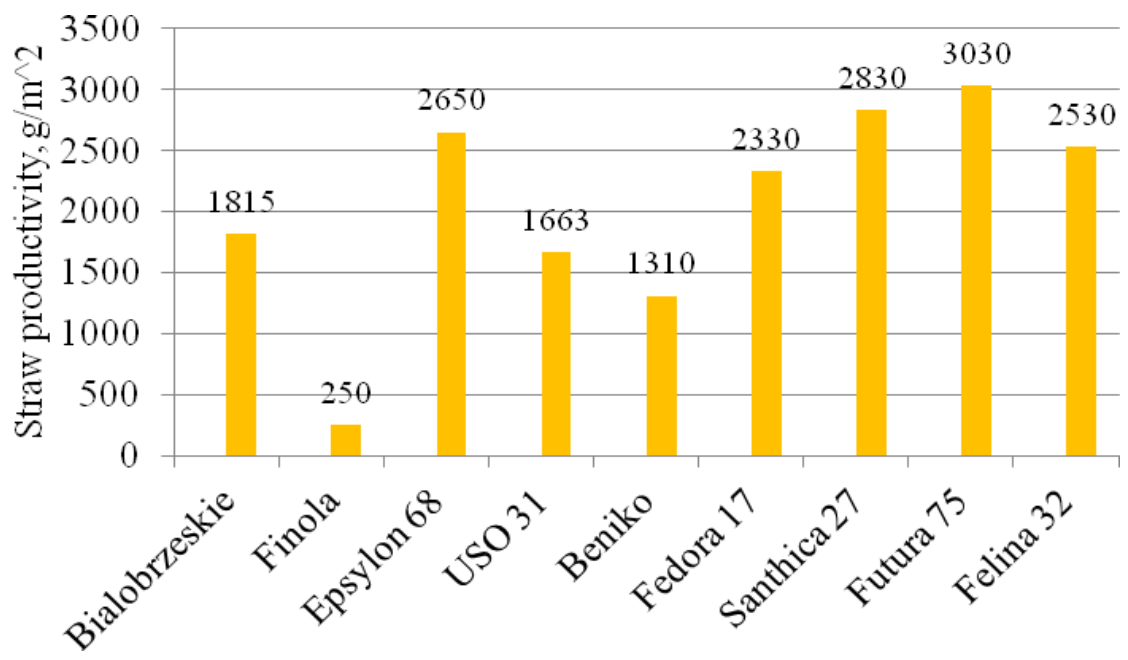

Fig.2. Straw productivity of diferent cultivars

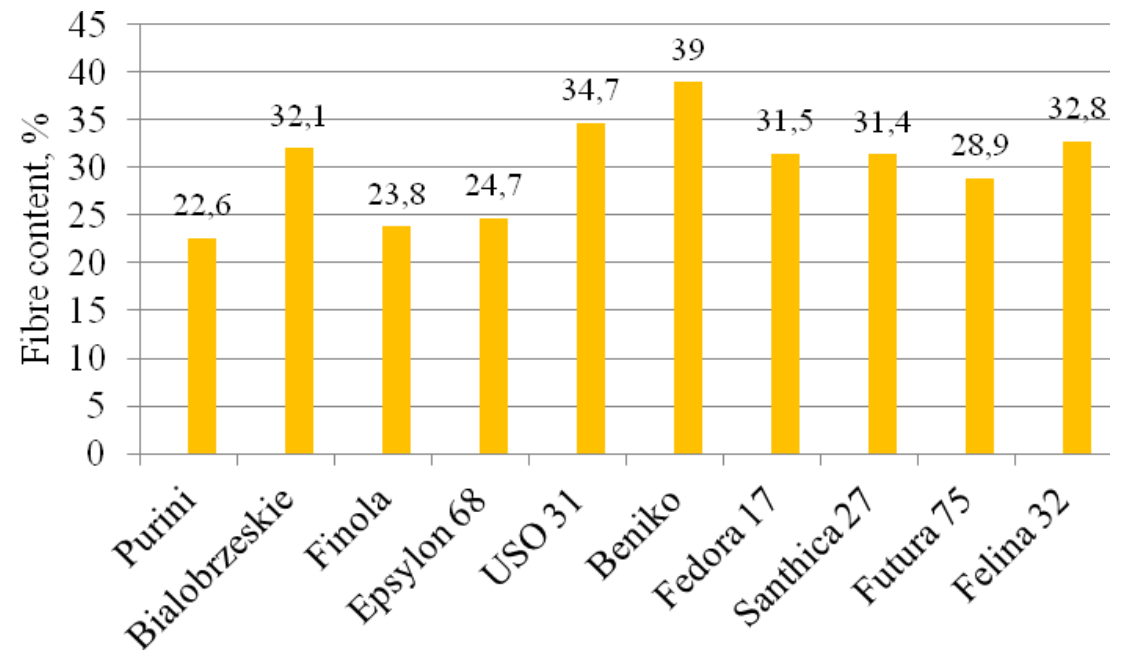

Fig.3. Fiber content in the straws

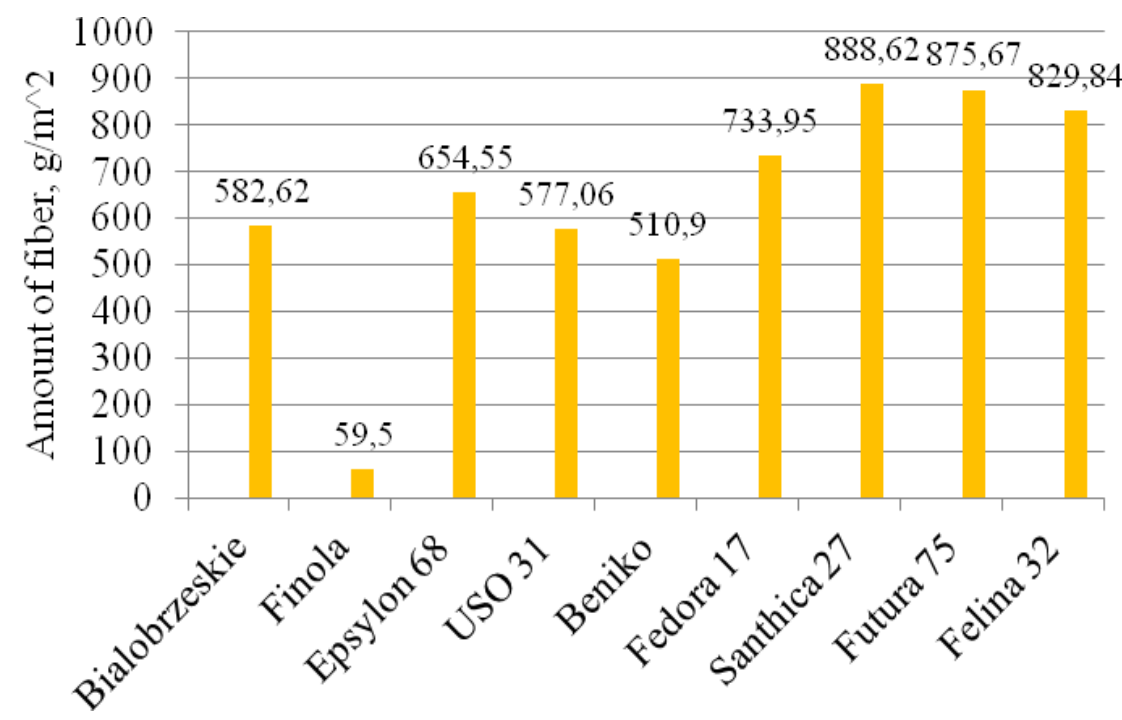

Fig.4. Obtained amount of fiber from one square meter 


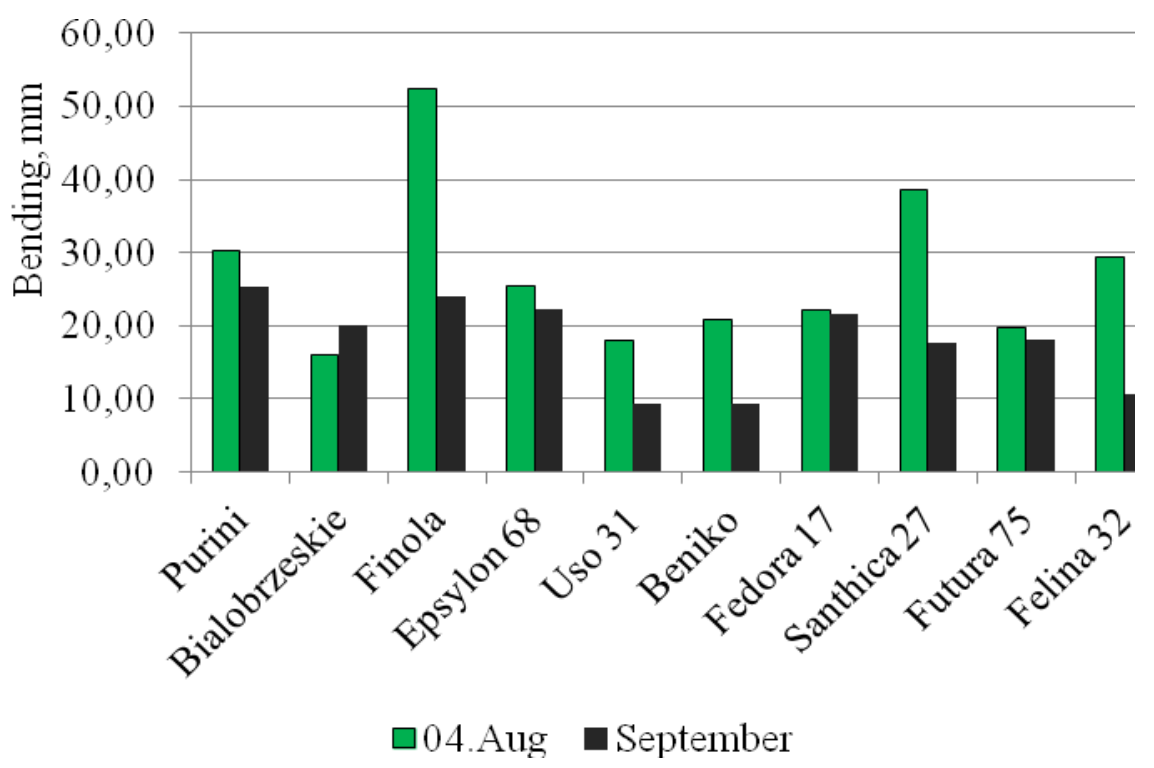

Fig. 5. Bending of fibre bundle ends from horizontal possition

The largest fiber flexibility (see Fig.5) has hemp fibres of varieties Purini, Finola, Epsilon 68 and Fedora 17. Besides for most of the fibers flexibility decreases with the maturity of plants. Only if we compare flexibility of Bialobrzeskie hemp fibres, then it is higher for fibres which are harvested in September compared with August fibres. Fig. 6 shows the changes of fibre linear density. There is no correlation between plant maturity and fibre linear density. Mainly it depends on the hemp fibre obtaining and pretreatment technological processes. The finest fibers in this case are derived from the Purini and Finola varieties, but the largest linear density is for Felina 32 variety.

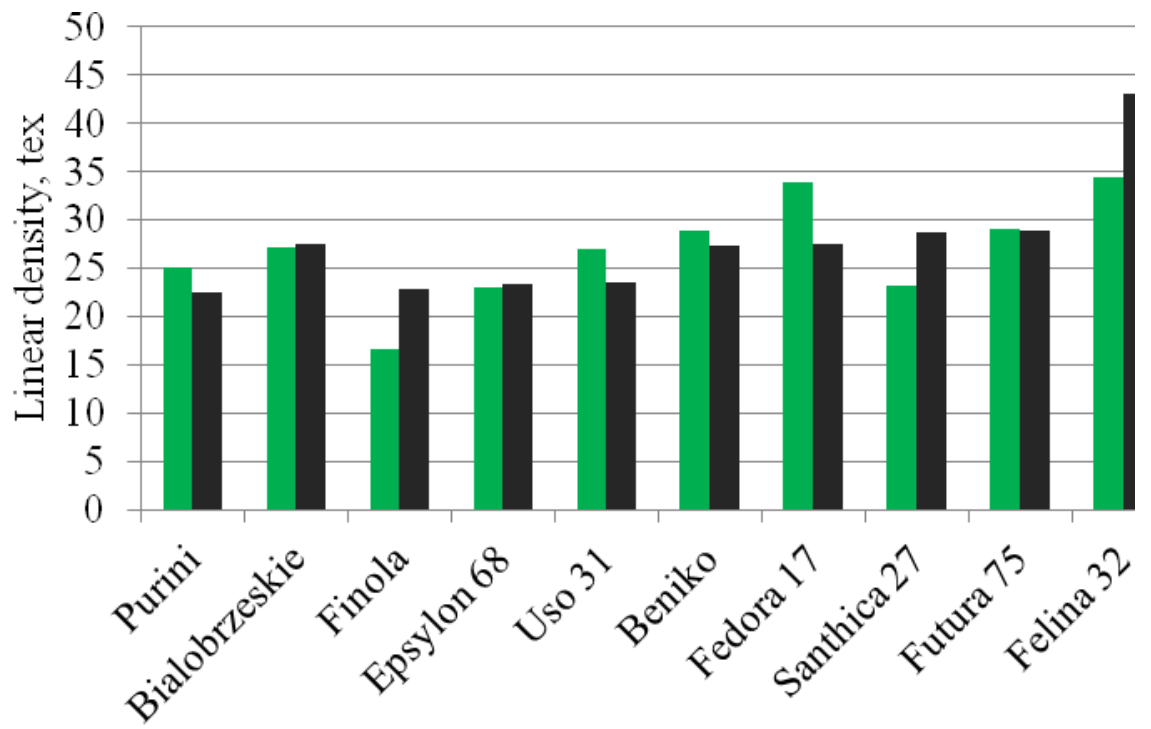

-04.Aug $\square$ September

Fig. 6. Fiber linear density

Values of hemp fiber breaking tenacity and extension at break are given in Table 1 and force extension curves in the Fig. 7. and 8. The highest strength has fibres from varieties Bialobrzeskie, USO 31un Futura 75, the lowest from Fedora 17 and Santhica 27. Basically the 
strength is higher for all hemp fibres which were harvested in August than in September. The exception is the only variety Epsylon 68, the experimentally determined average strength of which is slightly higher in September than in August. Although it should be noted that this difference is very small.

\section{Strength characteristics of hemp fibre}

Table 1.

\begin{tabular}{|c|c|c|c|c|}
\hline \multirow{2}{*}{ Hemp variety } & \multicolumn{2}{|c|}{ Breaking tenacity (cN/tex) } & \multicolumn{2}{c|}{ Extension (\%) } \\
\cline { 2 - 5 } & August & September & August & September \\
\hline Beniko & 10,37 & 7,34 & 2,33 & 0,87 \\
\hline Bialobrzeskie & 13,81 & 11,49 & 2,03 & 1,59 \\
\hline Epsylon 68 & 9,68 & 9,76 & 2,85 & 1,33 \\
\hline Fedora 17 & 8,06 & 7,86 & 2,14 & 1,24 \\
\hline Felina 32 & 9,23 & 9,70 & 2,05 & 1,33 \\
\hline Fenola & 8,10 & 12,26 & 2,04 & 2,42 \\
\hline Futura 75 & 11,20 & 10,87 & 1,75 & 1,22 \\
\hline Pūrinii & 9,78 & 11,85 & 1,84 & 1,84 \\
\hline Santhica 27 & 8,51 & 8,11 & 2,55 & 1,07 \\
\hline Uso 31 & 11,72 & 10,59 & 2,26 & 1,20 \\
\hline
\end{tabular}

Hemp fiber breaking elongation ability is very small. For September harvested hemp fibres it is between $0.87-2: 42 \%$, but for August fibres it is from $1.75-2.85 \%$. Consequently we can conclude that August fibers elongate better than hemp fibres harvested already in September.

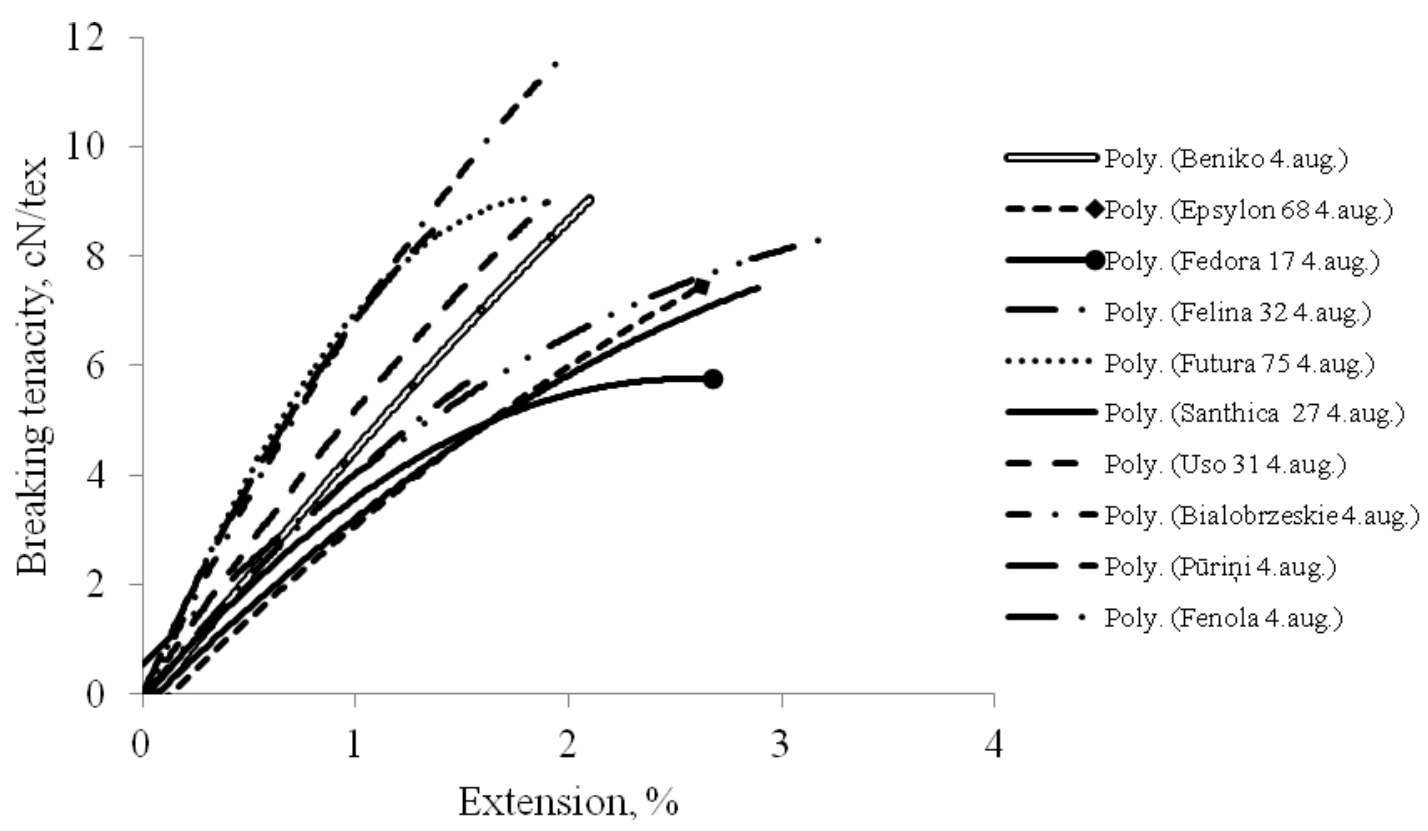

Fig. 7. Force extension curves for fibers of different varieties harvested in August 4

The higher strength and elongation ability of hemp fibres harvested in August can be explained with the increase of lignin content during and after plant flowering. 


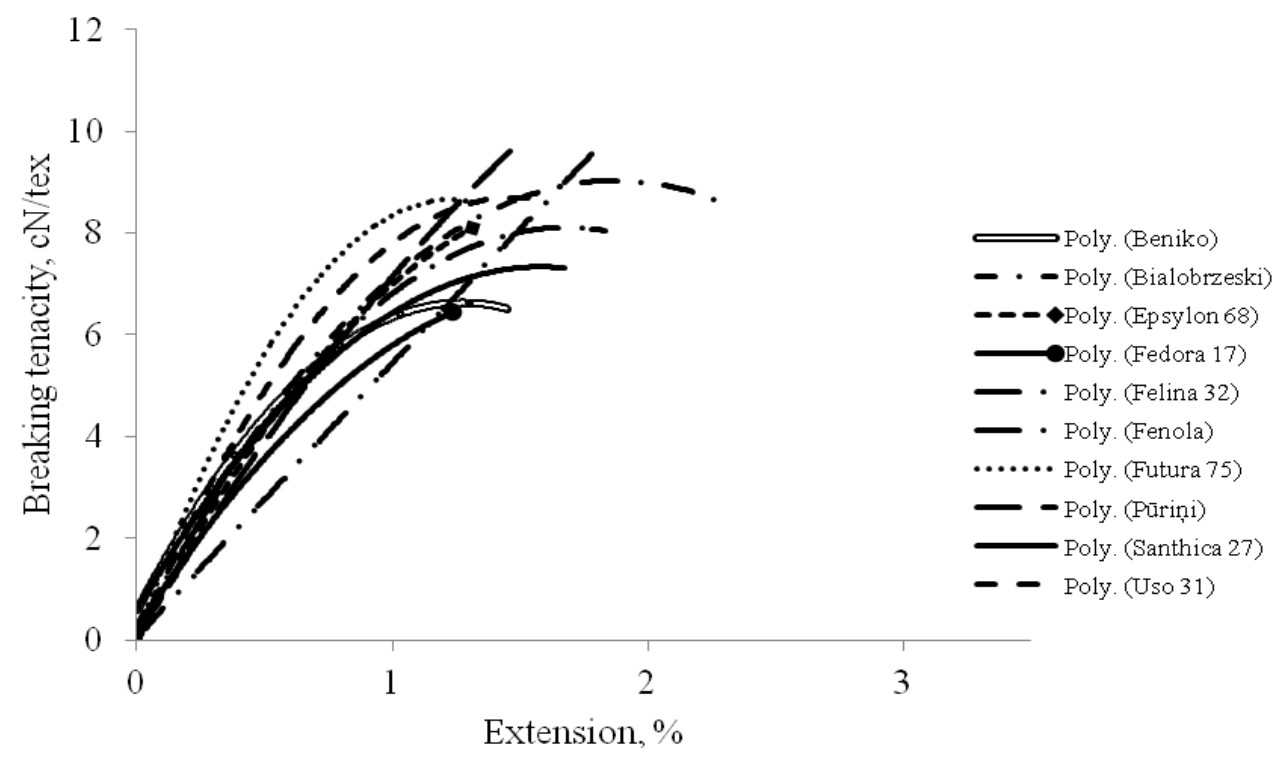

Fig. 8. Force extension curves for fibers of different varieties harvested in September

It can be concluded:

\section{Conclusions}

- The largest mass of fibers can be obtained from varieties Santhica 27, Futura 75 and Felina 32.

- The strongest fibres can be obtained from varieties Bialobrzeskie, USO 31un Futura 75.

- The most flexible fibres are from varieties Purini, Finola, Epsilon 68 and Fedora 17.

- Hemp fibres form local variety Purini have high flexibility and good tensile charecteristics.

- It is recommended to harvest hemp straws when they are still immature to get better fibre quality.

- Additional research should be done to find out better harvesting time for hemp fibres before flowering, at flowering or immediately after flowering.

\section{References}

1. Bennett S. J., Snell R., Wright D. Effect of variety, seed rate and time of cutting on fibre yield of dewretted hemp. Industrial Crops and Products 24. 2006. P. 79-86

2. Thygesen A. Properties of hemp polymer composites - An optimisation of fibre properties using novel defibration methods ad fibre characterisation, Risø National Laboratory, Roskilde, Denmark, 2006

3. Blackburn, R.S. (Editor). Biodegradable and Sustainable Fibres. Cambridge, GBR: Woodhead Publishing, Limited, 2005

4. Djunaedi K. Development of a Sliver PolymerMatrix Composite( SPMC) using Flax Fibers and Epoxy / Acrylated Epoxidized Soybean Oil Resin, Raleigh, North Carolina, 2007

5. Loyd E.H., D. Seber Bast fiber applications for composites, Columbus: Wood Handbook, 1996

6. Dhakal H.N., Richardson M.O.W., Zhang Z.Y., Effect of water absorption on the mechanical properties of hemp fibre reinforced unsaturated polyester composites, UK: Science Direct, 2006

7. Sedelnik N. Properties of hemp fibre cottonised by biological modification of hemp hackling noils, Poznan, Poland: Institute of natural fibres, 2004

8. Thygesen L. G., Asgharipour M. R. The effects of growth and storage conditions on dislocations in hemp fibres. Journal of Material Sciences, 2008, p. 3670-3673

9. Armaducci S., Zatta A., Pelatti F., Venturi G. Influence of agronomic factors on yield and quality of hemp (Cannabis sativa L.) fibre and implication for an innovative production system. Field Crops Research. 2008. P. $161-169$

10. Kozłowski K., Konczewicz W., Łukaszewska N., Strybe M., Oleszak G. The effect of agro technical factors on content and quality of hemp fiber. International Conference on Flax and Other Bast Plants. 2008., p.332-343. 